\title{
ADAPTIVE STATISTICAL ITERATIVE RECONSTRUCTION FOR OPTIMIZATION IMAGE QUALITY OF CT SCAN ABDOMEN
}

\author{
Lydia Purna $\left.W .^{a *}\right)$; Rini Indrati ${ }^{b}$; Arieyanti Biyono ${ }^{c}$ \\ ${ }^{a}$ Kedokteran Universitas Diponegoro ; \\ Jl. Prof Sudarto No. 13 Tembalang Semarang 50275 \\ ${ }^{b}$ Teknik Radiodiagnostik dan Radioterapi ; Poltekkes Kemenkes Semarang ; \\ Jl. Tirto Agung Pedalangan Semarang 50268 \\ c Sultan Agung Hospital Semarang ; \\ JL. Kaligawe Raya Km 4 Terboyo Kulon Genuk Semarang 50112
}

\begin{abstract}
Adaptive Statistical Iterative Reconstruction is a software used to reduce noise. Several hospitals have used the ASIR application with varying percentages among radiographers. The purpose of this study is to determine differences in noise and anatomical image information on variations in the percentage of ASIR and ASIR values that reveal optimal CT scan anatomic image information. This type of research is experimental, data were taken from 30 samples of reconstructive CT scan of the abdomen by giving four variations of ASIR $(0 \%, 40 \%, 60 \%$, and $80 \%)$. Noise measurement was done by placing the ROI size of $105.61 \mathrm{~mm} 2$ at three points: superior liver, inferior liver and middle of the aorta on the axial section. Data analysis used the One way Anova test to determine differences in noise, and Friedman test to determine differences in anatomical image information with a confidence level of $95 \%$. The results show that there were differences in anatomical image information on the variation of ASIR with p-values $<0.001$. The percentage ASIR of $40 \%$ was the optimal ASIR value for displaying CT images of abdominal with mean rank of 3,46. In arranging ASIR values, it is expected to consider other factors such as Spatial resolution.
\end{abstract}

Keywords: ASIR, Noise, Anatomical Inforation, CT Abdomen.

\section{Introduction}

CT scanning of the abdomen in patients is often complicated with artifacts and it relatively increases noise due to the abdomen being a thick and complex organ. One disadvantage of CT Abdomen is that the resulting image has a high noise level (Guzinski et al, 2016).

Noise is one of the parameters determining the image quality. Noise will affect the resolution contrast and spatial resolution; if the noise and the spatial resolution are high, the contrast resolution will decrease (Seeram, E., 2001).

One of the newest image reconstruction methods on MSCT Scan to minimize noise and improve image quality is by applying Adaptive Statistical Iterative Reconstruction or commonly referred to as ASIR (Vardhanabhuti, Loader,

*) Corresponding Author (Lydia Purna W)

E-mail: lydia.kuntjoro@gmail.com
Mitchell, Riordan, \& Roobottom, 2013),(Nagatani et al., 2015). Optimal image quality helps the accuracy in diagnosis, thus it can avoid errors in the diagnosis of patient illness (Bourne, 2010).

Previous study described that ASIR application is used in attempts to reduce noise and to improve image quality on head CT scan examination primarily in organs in the posterior fossa region (Flohr TG, et, 2005), (Guzinski et al., 2016). ASIR also influences noise management and increases anatomical information on CT stonography (Saifudin, et al, 2017)

One of the most recent methods in reconstructing MSCT Scan images to minimize noise and to improve the quality of CT Scan images is by using the Adaptive Statistical Iterative Reconstruction (ASIR) application (Flottmann F, 2016) (McCollough CH. 2016). (Geyer LL, 2015). ASIR was developed into a corrective application that is used to overcome 
noise. (Silva AC, 2010). ASIR has a percentage value ranging from $0 \%$ to $100 \%$. (Hara $A K, 2009$ ).

CT scan of the abdomen at the hospital has various operational standards in using ASIR software. This study was conducted to determine differences in noise and image information on variations in the percentage of ASIR values and to determine the percentage of ASIR values that can provide the most optimal anatomical CT scan image information.

\section{Methods}

This type of research is experimental. Data were taken from 30 samples of CT scan Abdomen reconstruction images by giving four variations of ASIR percentage values $(0 \%, 40 \%$, $60 \%$, and $80 \%$ ). Measurement of the noise value was done by placing ROI size of $105.61 \mathrm{~mm} 2$ in three points namely the superior liver, inferior liver and middle of the aorta on the axial section. (Nesset 2000) (Moeller, 2001). The assessment of anatomic image information was done by observing the results of variations in the percentage of ASIR values by two radiologists on the level of anatomical clarity of the liver parenchym and intrahepatic portal vein, veins in the liver, hilum structure of the liver, gallbladder wall, aortic and inferior vena cava., (Moeller, 2001). Data analysis used the One way Anova test continuing Post Hoct test with LSD test and Friedman test with a confidence level of $95 \%$. (Sugiyono, 2011)

\section{Result and Discussion}

Characteristics of the sample in this study were 30 patients who underwent $\mathrm{CT}$ scan of the abdomen. The patients consisted of 13 men and 17 women with an age range of $47-68$ years.
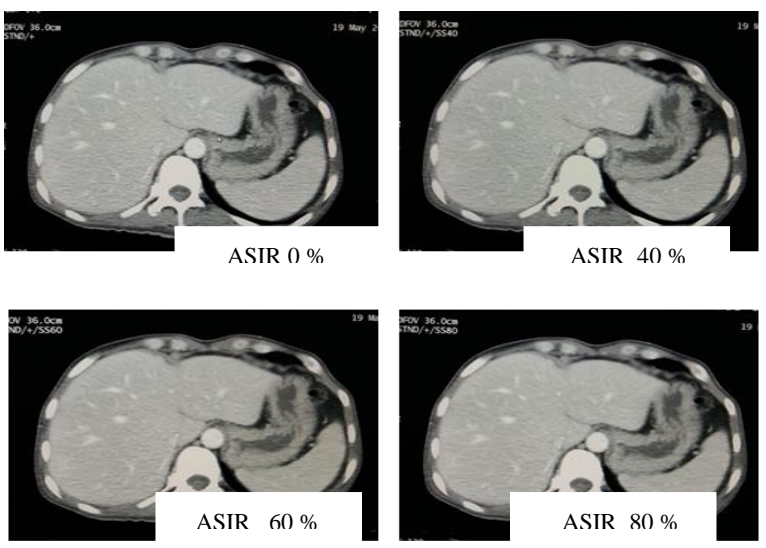

Figure 1. Image of CT Abdomen resulting from reconstruction with variation of ASIR
Figure 1. shows the results of abdominal CT and reconstruction results with varying ASIR values.

Noise measurements performed on the superior liver, inferior liver and middle of the aorta on the axial section give an average value as shown in Figure 2. The highest noise value was 15.34 in the initial image or ASIR $0 \%$, while the lowest was 8.57 in the provision of ASIR values $80 \%$.

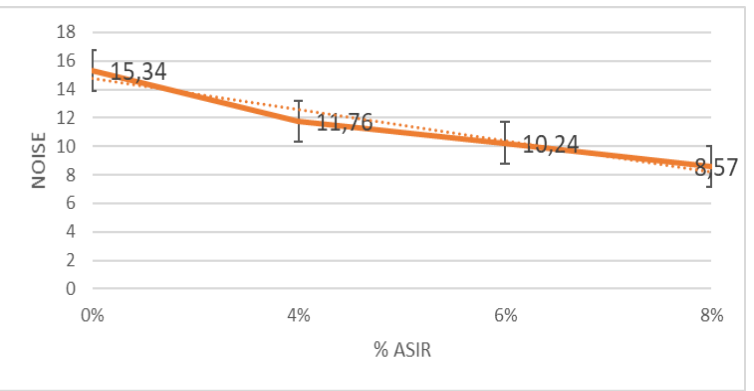

Figure 2. Graph of noise on ASIR variations

Noise value at each percentage ASIR was $0 \%=15.34$, at $\mathrm{ASIR} 4 \%=11.76$, at $\mathrm{ASIR} 6 \%=$ 10.24 and at ASIR $8 \%=8.57$ The graph above shows a tendency to decrease the noise value on increasing percentage ASIR value.

The results of the different noise tests on ASIR variations were carried out with the Anova Test as in table 1.

Table 1. Noise difference in ASIR variation with

\begin{tabular}{cc}
\multicolumn{2}{c}{ the Anova Test } \\
\hline Variabel & p-value \\
\hline ASIR 0\% & $<0,001$ \\
ASIR 40\% & \\
ASIR 60\% & \\
ASIR 80\% & \\
\hline
\end{tabular}

The analysis results with the anova test show that there were differences in the value of noise in ASIR variations with $p$-value $<0.001(p<0.05)$. The next test was to see the difference in noise values between variations with the Post hoc Test. Post hoc test results with LSD are shown in table 2.

Table 2. Noise differences between ARSIR using post hoc test with LSD

\begin{tabular}{cc}
\hline Variabel & p value \\
\hline ASIR 0\% - ASIR $40 \%$ & $<0,001$ \\
ASIR 0\% - ASIR 60\% & 0,027 \\
ASIR 0\% - ASIR 80\% & 0,018 \\
ASIR 40\% - ASIR 60\% & 0,037 \\
ASIR 40\% - ASIR 80\% & 0,045 \\
ASIR 60\% - ASIR 80\% & 0,052 \\
\hline
\end{tabular}


The post hoc test with LSD shows that there were differences in noise between ASIR settings, except between $60 \%$ ASIR and $80 \%$ ASIR.

In the anatomical image information, the results of the assessment of each respondent were first carried out the alignment test (Reliability Inter Observer) by using the Reliability Test. The alignment test results between observers as shown in table 3 .

Table 3. Results of the Test of Equality of Anatomical Assessment on the CT Scan Abdomen Image

\begin{tabular}{ccc}
\hline Variabel & Koeef. kappa & p-value \\
\hline $\begin{array}{l}\text { Observer 1 } \\
\text { Observer 2 }\end{array}$ & 0,871 & 0,001 \\
\hline
\end{tabular}

This test was conducted to determine whether there were significant differences in anatomical image information on axial CT scan images of the abdomen with variations in the percentage of ASIR values of $0 \%, 40 \%, 60 \%$ and $80 \%$. The sample used in this study was ordinal data of more than two groups and unpaired data, so the statistical test used was the Friedman Test, show in tabel 4 .

Table 4. Anatomical Information Difference Test on ASIR Variations with Friedman test

\begin{tabular}{ccc}
\hline Variabel & Mean rank & p-value \\
\hline ASIR 0\% & 1,09 & \\
ASIR $40 \%$ & 3,46 & $<0,001$ \\
ASIR $60 \%$ & 2,97 & \\
ASIR $80 \%$ & 2,48 & \\
\hline
\end{tabular}

The results of the analysis using the Friedman Test show that there were differences in anatomical information on CT Scan abdomen on the use of ASIR reconstruction. The Friedman Test results also obtained the average ranking results of each ASIR value. The highest results from the Friedman mean rank test on the variation of ASIR percentage values to the anatomical image information show the optimal image at a value of $40 \%$ ASIR percentage on abdominal CT scan images having the highest mean rank of 3.46. This means that image reconstructions with a percentage of ASIR value of $40 \%$ are the best percentage of ASIR values because it can display optimal anatomical image information compared to other variations of ASIR value

In this study, the noise value decreased with the increase in the percentage of ASIR applications used on CT scan abdomen images. At the percentage of $80 \%$ ASIR value, the lowest average noise value was 8.57. The resulting image is the result of using the percentage of ASIR to reduce noise in the new image produced. (Geyer, LL, 2015)

The results of this study are in accordance with previous research stating that ASIR is a method of reconstructing algorithms on CT Scan with the basic principle of estimating data to produce reconstruction images by reducing noise (Jonathon, 2010)

Friedman test shows differences in anatomical information on abdominal CT scan in the variation of ASIR percentage with $\mathrm{p}$-value $<0.001$.

The application of ASIR produces a good image on CT Scan images with different density levels and complex, so that this high-noise image can be applied with ASIR to reduce noise in the resulting reconstruction image. The most optimal application of ASIR results in the resulting image not being able to display firm boundaries between organs firmly due to over smoothing or the number of free noise displays that can appear as artifacts on the image. (Leiner T, 2011). This over smoothing picture has less detail so the diagnostic picture is less clear. (Liu L. 2014)

In this research, the best anatomical image information was obtained from the application of ASIR $40 \%$, because the images produced in the $40 \%$ ASIR application had the most optimal image quality, namely the spatial resolution of organs or clear boundaries between organs. The anatomical clarity of the application of ASIR $40 \%$ is caused by the fact that noise can be reduced without overdoing it so there is no over smooting which will cause the image to lose detail. (Saifudin, et al, 2017)

\section{Conclusion and Suggestion}

There are differences in the value of noise and CT Scann Abdomen anatomical information information on ASIR value variations. The percentage of ASIR value of $40 \%$ showing optimal anatomical image information is $40 \%$.

In arranging ASIR values, it is expected to consider other factors such as Spatial resolution.

\section{Acknowledgements}

Thanks to the Director of Poltekkes Kemenkes Semarang for the research activities. Thanks also to the Director of Sultan Agung Semarang for the permission to conduct research, especially the Radiology Installation for assistance at the time of data collection. 


\section{Refferences}

Bourne, R. Fundamentals of Digital Imaging in Medicine. Springer London Dordrecht Heidelberg, 2010, 87-88.

Flohr TG, Schaller S, Stierstorfer K, Bruder H, Ohnesorge BM, Schoepf UJ. Multi Detector Row CT Systems and ImageReconstruction Techniques. RSNA. 2005; (30 cm).

Flottmann F, Kabath J, Illies T, Schneider T, Buhk J. Iterative Reconstruction Improve Both Objective and Subjective Image Quality in Acute Stroke CTP. 2016;72:1-14. doi:10.1371/journal.pone.0150103.

Geyer LL, Schoepf UJ, Meinel FG, et al. State of the Art: Iterative CT Reconstruction Techniques. RSNA. 2015;276(2):339-357.

Guzinski M, Waszczuk Ł, Marek JS. Head CT: Image quality improvement of posterior fossa and radiation dose reduction with ASiR - comparative studies of CT head examinations. 2016. doi:10.1007/s00330015-4183-4.Hara, A.K. et al., 2009. Iterative Reconstruction Technique for Reducing Body Radiation Dose at CT: Feasibility Study. Gastrointestinal Imaging.

Hara AK, Paden Roberet G, Silva A, Pavlicek William.Iterative Reconstruction Technique for Reducing Body Radiation Dose at CT: Feasibility Study.AJR 2009,193:764-771

Leipsic Jonathon, LaBountry T, Heilbron B, Taylor C. Adaptive Statistical Iterative Reconstruction; Assessment of Image Noise and Image Quality in Coronary CT Angiography.AJR 2010.195:649-654
Leiner T,Velthus B, Gietema.Iterative Reconstruction for Reducing Radiation Dose at CT: Review of Technique and Initial Experience.ECR 2011.

Liu L. 2014. Model-based Iterative Reconstruction: A Promising Algorithm for Today's Computed tomography Imaging. J Med Imaging Radiat Sci.

McCollough CH, Fletcher JG, Yu L, Fletcher JG. Dual- and Multi-Energy CT: Principles, Technical Approaches, and Clinical Applications. RSNA. 2015;276(3):637653.Morgan, M.S.C. \& Pearle, M.S., 2016. Medical management of renal stones. , 2005, pp.1-1

Moeller T, Reif Emil. 2001. Pocket Atlas of Radiographic Positioning. Thieme

Nesseth, Roland. 2000. procedure and Documentation for CT and MRI. Mc GrawHill Medical Publishing Division, Kansas.

Seeram, E., 2001. Computed Tomography: Physical Principles, Clinical Applications and Qualitu Control,

Silva AC, Lawder HJ, Hara A, Kujak J. Innovations in CT Dose Reduction Strategy: Application of the Adaptive Statistical Iterative Reconstruction Algorithm. Am J Radiol. 2010;(January):191199. doi:10.2214/AJR.09.2953.

Saifudin, Hermina Sukmaningtyas, Djamaluddin Ramlan, Ari Suwondo, M. Choiroel Anwar, Rini Indrati. Application of ASIR and Windowing to Image Anatomical Information of CT Scan Stonography.Int J of Allied Med Sci and Clin Res 2017; 5(4): 941-946

Sugiyono. Metode PenelitianKuantitatif, Kualitatif dan $R \mathcal{E}$ D. Bandung: Alfabeta. 2011. 